\title{
A Study on Cloud Computing and Service Market: International Context with Reference to India
}

\author{
P. K. Paul ${ }^{1}$, Bashiru Aremu ${ }^{2}$, P. S. Aithal ${ }^{3}$, Ricardo Saavedra ${ }^{4}$ and Ripu Ranjan Sinha ${ }^{5}$ \\ ${ }^{1}$ Executive Director, MCIS, Department of CIS, Information Scientist (Offg.), Raiganj University, India \\ ${ }^{2}$ Vice-Chancellor, Crown University, Intl. Chartered Inc. (CUICI) Argentina Campus, South America. \\ ${ }^{3}$ Vice Chancellor, Srinivas University, Karnataka, India \\ ${ }^{4}$ Director \& Chair, International Inter-University Programs, Azteca University, México, America \\ ${ }^{5}$ Pro Vice-Chancellor (Asian Region), Commonwealth Vocational University, Tonga, Oceania. \\ E-mail: pkpaul.infotech@gmail.com
}

\begin{abstract}
Cloud computing is one of the emerging areas and components within the Information Technology space. Cloud Computing is a kind of virtualization techniques which is achieved by the internet and similar services. Cloud Computing is growing rapidly within Information Technology. This is responsible for the creation of a healthy virtual information technology infrastructure. Cloud Computing is very much important for distributing IT Infrastructure for the concerned organizations and its branches or sister organizations. Cloud Computing is rapidly moving towards the government and public sectors as well due to its benefits and opportunities. Cloud Computing is also called as Virtualization Technology. Within the support of Cloud Computing, there are many service models and types that are emerging viz. Software, Applications, Platforms and Operating Systems, Hardware and infrastructure, Contents and Information, etc. The emerging other technologies are also increasing and many of them relate to the Cloud Computing viz. Big Data, Analytics, Internet of Things (IoT), etc. The market of the cloud also depends on various other things and it is important to note that, apart from the existing established IT organizations and companies, there are many new specially dedicated cloud service providers also emerging rapidly. Cloud Computing Services and its emergence including the current market scenario is provided in this paper including some of the companies and their basic services as well.

Keywords: Cloud Computing, Big Data, Service Oriented Architecture, Virtualization, Data Centre, Cloud Market, Cloud Technologies
\end{abstract}

\section{INTRODUCTION}

Cloud Computing as a branch of Information Technology is rapidly growing and this is very close with the main components of Information Technology viz. Database Technology, Network Technology, Web Technology, Multimedia Technology, Software Technology, etc case to case basis; depending upon the requirement [1], [5], [15]. Further, Cloud Computing is close with other super specialties or emerging technologies viz. -
1. Big Data
2. Analytics
3. Internet of Things (IoT)
4. Edge Computing
5. Fog Computing, etc.

The market of Virtualization Technology is growing in recent past and many companies are doing well in promoting and offering cloud markets and within this segment, the popular are IBM Cloud, Amazon Web Services, Microsoft, Dell, VMW are, etc. Like international scenario India is also doing nice in developing cloud and allied digital space rapidly [2], [11], [16]. The internet users in India are growing rapidly and here cloud-based services also promoting/uses; directly and indirectly. In coming years it will be more developed and rapid with Digital India initiative undertaken by the Government of India for the development of the Communication Systems and here Cloud Computing uses in large scale is important for the transition of high-speed 4G LTE, G wireless technologies and these can be only possible by healthy cloud based data center infrastructure [3], [4], [21]. The scenario of Cloud computing in 2020 and the previous one are different in many contexts and it is healthy and more mature, more focused on vertical delivery and emerging services. Further, regarding the sales ground war as the leading vendor's battle for market share.

\section{OBJECTIVES}

This paper is conceptual in nature and mainly concentrated to deal with following aim and objective (but not limited to):

1. To learn about the basics of Cloud Computing including its features and functions in a brief manner.

2. To learn about the basic types and service models of the Cloud Computing and Virtualization in brief.

3. To get a concise picture of Cloud Computing service models emergence in International and in the Indian market.

4. To learn about the few organizations and companies which are rapidly growing in International and Indian market.

To get the knowledge of challenges and issues in respect of the Cloud Computing market in the contemporary scenario. 


\section{A. Cloud Computing: Fundamentals}

Cloud computing is the emerging and one of the modern Computing and Information Technology services [9], [10], [17]. It is the offering of Information Technology services from the remote places mainly using the internet and among the service gradients, few important are include-

1. Software and Applications

2. Platforms and Operating Systems

3. Storage and database

4. Hardware and infrastructure

5. Contents and Information, etc

Cloud computing is a kind of remote based computer and system support, mainly the data storage by the active management by the user. The term Cloud computing synonymously also called as Data Centre, though it may be treated as a partial definition only. Cloud Computing is available to many users with different kinds of functions, features, etc distributed in different locations and organizations at a time by the use of a centralized server. Close connection to the user is called as Edge Server [12], [19], [27]. Cloud Computing can be typed as three viz. Public Cloud Computing, Private Cloud Computing, Hybrid Cloud Computing, etc.

Public Cloud Computing, simply called as Public Cloud, which is the virtualization or remote based services using the internet. Public Cloud Computing is offered by the third-party ad available in multiple locations and it is little cost effective as well. Private Cloud Computing is another mode of Cloud Computing and called as Private Cloud.

This is responsible for in-house or concerned organizationbased cloud-based services and strictly established, managed and operated from the concerned organization. It is a little safer and having security due to its operation mode.

In sensitive business and organizations, these are highly practiced. Hybrid Cloud Computing is the combination of both the Cloud Computing (i.e. public \& private) and may be accessible and useful based on need and situation [6], [7], [20]. Hence cloud computing comes with following features and characteristics viz.

1. Elasticity

2. Scalability

3. Cost Effective

4. Remote Based

5. Multiple Sharing

6. Huge Data and Infrastructure

7. Dependency, etc.

Worldwide the Cloud Computing uses are growing in different kinds of organizations and institutions and as a result, various vendors and companies have started working on cloud-based solutions [8], [13], [18].

\section{B. Cloud Service Providers}

Cloud computing service providers aspects can be classified based on situation, conditions and types. There are different kinds of Cloud Computing we already learned about these viz. Public Cloud, Private Cloud and Hybrid Cloud Computing and based on these types the service providers are also different. Further, based on services Cloud Computing can be different models viz. (but not limited to):
1. Software as a Service
2. Platform as a Service
3. Infrastructure as a Service
4. Storage as a Service
5. Security as a Service, etc.

Cloud computing service providers can be noted as wellestablished organizations and companies and newcomers [14], [22], [29].

Among the service providers, few important are include-

1. Amazon Web Services

2. Cloud ways Cloud Services

3. Digital ocean's droplet

4. Kamatera Cloud Solutions

5. Rack space Cloud Solutions

6. Massive Grid Cloud Solutions

7. Alibaba Cloud Solutions

8. The Liquid Web Cloud Solutions

9. Azure Cloud Solutions

10. Google Cloud

11. VM ware Cloud Solutions

12. Oracle Cloud

13. Verizon Cloud computing

14. Navi Site Cloud Solutions

15. IBM Cloud

16. Open Nebula Cloud Solutions

17. Pivotal Cloud Foundry

18. Cloud sigma Cloud Solutions

19. Dell Cloud

20. One Portal Rapid Cloud Solutions

21. Quadra net Cloud Solutions

22. Phoenix NAP Cloud

23. Science Soft Cloud Solutions

24. Adobe Cloud

25. Red Hat Cloud

26. SAP Cloud

27. Drop box Cloud Solutions

28. Egnyte Cloud

29. Sales force Cloud

Among these companies the major and popular brands are Microsoft, Google, Dell, IBM, Oracle and as far as other specially dedicated cloud services are concerned important are Amazon Web Services, VMware Cloud Solutions, Sales force Cloud, etc [19], [23], [24]. 


\section{Cloud Computing \& Market}

Cloud Computing supports are increasing day by day and there are different things need to check out before the establishment and implementation of the Cloud Computing viz.:

1. Region supported or not this thing essential to check out as most of the Cloud Computing support are from Public Cloud so all the services may not be available always and in all the regions or part.

2. Though Cloud Computing is cost effective, but it is essential to check the cost for the service and also permitted in the budget or not.

3. As far as outsourcing company is concerned, it is essential to follow or check the legal aspects.

4. Initial training cost of the employees regarding the introduction of Cloud Service Platform is also an important and valuable aspect and concern.

5. Customer support is another issue, which also needs to check; whether it is offered or not.

6. Successful track records of the services including the stability/uptime/reliability are also essential to followup before the establishment and implementation of the Cloud Computing.

7. Reviews of the concerned cloud service providers i.e. company is also essential to check for better and healthy results [21], [25], [26].

Cloud Computing market is increasing in both; by its service providers and by the client itself. There are different services, and all these are increasing. As far as types are concerned, this is also emerging. Within the developing country, India and China are important names due to several concerns and potentialities in the Cloud Computing business. As far as India is concerned, it has over 460 million internet users and as per rank, it holds the second position worldwide after China.

And according to a study of Statista, it is expected to reach the internet users in India would be around 635.8 million and importantly all these internet users will use Cloud Computing and allied services parallel way. The rise in Internet and Cloud use may be due to the Digital India initiative undertaken by the Government of India. And this trend will rise in the coming years as well. Moreover, the transition of telecommunications companies and service providers to the high-speed 4G LTE and more expected 5G wireless technologies would change the data and cloud need and gradually healthy data center infrastructure.

Many experts say about the current growing market on cloud and among them Akash Ambani, The Managing Director, Reliance Jio InfoComm one of the leading cloud based telecom service “ India's public cloud market is estimated to be $\$ 2.6$ billion in 2018, and over $\$ 4$ billion by 2020,"Regarding the worldwide market on Cloud Computing it is noted that in the year 2018 total market for the Software as a Service (SaaS) 85.7 US Billion Dollars; whereas the Infrastructure as a Service was 32.4 US Billion Dollars. Among the new category of service model i.e. Security (Security as a Service), the market was touched at 10.5 US Billion Dollars, internationally in the same year. According to a report of the Gartner, the expected growth in Cloud Segment are huge and these are depicted in Table 1.

\section{TABLE 1 CLOUD COMPUTING \& ITS GROWTH ACCORDING TO THE GARTNER, WORLDWIDE}

\begin{tabular}{|l|c|c|c|c|c|}
\hline Types & $\mathbf{2 0 1 8}$ & $\mathbf{2 0 1 9}$ & $\mathbf{2 0 2 0}$ & $\mathbf{2 0 2 1}$ & $\mathbf{2 0 2 0}$ \\
\hline $\begin{array}{l}\text { Cloud } \\
\text { Business } \\
\text { Process } \\
\text { Services } \\
\text { BPasS) }\end{array}$ & 41.7 & 43.7 & 46.9 & 50.2 & 53.8 \\
\hline $\begin{array}{l}\text { Cloud } \\
\text { Application } \\
\text { Infrastructure } \\
\text { Service } \\
\text { PaaS) }\end{array}$ & 26.4 & 32.2 & 39.7 & 48.3 & 58.0 \\
\hline $\begin{array}{l}\text { Cloud } \\
\text { Application } \\
\text { Services } \\
\text { (SaaS) }\end{array}$ & 85.7 & 99.5 & 116.0 & 133.0 & 151.1 \\
\hline $\begin{array}{l}\text { Cloud } \\
\text { Management } \\
\text { and Security } \\
\text { Services }\end{array}$ & 10.5 & 12.0 & 13.8 & 15.7 & 17.6 \\
\hline $\begin{array}{l}\text { Cloud System } \\
\text { Infrastructure } \\
\text { (IaaS) }\end{array}$ & 32.4 & 40.3 & 50.0 & 61.3 & 74.1 \\
\hline $\begin{array}{l}\text { Total Market } \\
\text { Plas }\end{array}$ & 196.7 & 227.8 & 266.4 & 308.5 & 354.6 \\
\hline
\end{tabular}

According to the study, it is noted that the highest expected growth according to the Gartner are SaaS and IaaS than other service models. And these expected changes are depicted in Fig: 1. Internationally the Cloud Computing market is different and there are different norms and regulations in this segment. As far as India is concerned, major Cloud Service Providers which have started in India include (but not limited to the following: among the major)-

1. Google

2. Microsoft

3. Alibaba Cloud

4. Amazon, etc.

However, there are many national players and they have many advantages in India, including setting the establishment, a survey on market, elasticity on the technologies, etc. For example, Ctrl S is offering Asia's largest Tier 4 data center services, NxtGencomes with the features of Dev Cloud, Machine Learning, Artificial Intelligence for urbanization and AI, Intelligent services, etc. It is important to note that, in India and worldwide Cloud Computing becomes more mature and moving towards multi cloud services powered by AI, Machine Learning, Big Data Analytics solutions [10], [18]. 


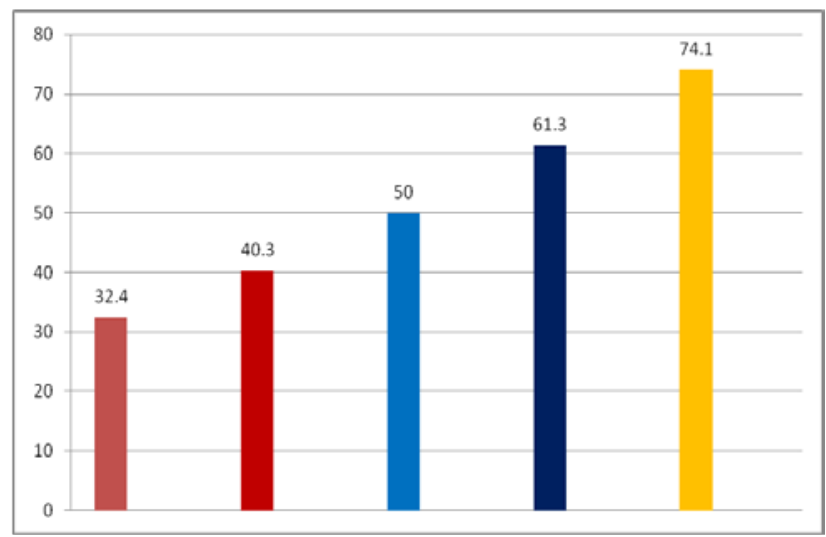

Fig: 1 Depicted the Growth and Expectation of Iaas as per Gartner Report from 2018 to 2022

All the MNCs are coming with various services viz. Amazon Web Services, Cloud Services from the Microsoft Azure, and Google Cloud, Cloud Services from the Dell Technologies, VMware Cloud Services and deployments, Sales force Cloud, etc and it is important to find out the potential issues, concern by the consumers before getting the cloud based services.

Cloud based service providers and companies are enhancing the organizations towards the quickly and rapidly changing environment which are scalable and also in a massive increase in demand for their services due to more and more activities in online systems business activities, education, and training, government and administration, entertainment, etc. Cloud computing is also helpful in improving healthcare services by the remote services and in this regard following cloud computing services companies are important viz. - Amazon (Cloud Services-Amazon Web Services), Alphabet, Google (Google Cloud), and Microsoft (Cloud Services-Azure).

According to the current CEO of Alibaba, Daniel Zhang, that Alibaba's future is centered on cloud regarding its business, further, he added once $7 \%$ of the company's revenue was dedicated to cloud but the fact now changed radically. Today it is operating 10 (ten) data centers only in China and internationally the number is 11 (Eleven).

It is a universal fact that, cloud computing is the biggest activity within the enterprise technology and established and newcomers including startups are rising gradually and as a result, cloud computing is a kind of metaphor for remote based services and servers based on the Internet. As far as Public Cloud Computing is concerned among the service providers important are Microsoft and AWS., Internationally the Cloud Computing market can be growing USD 272.0 billion in 2018 to USD 623.3 billion by 2023 as far as Report Linker is concerned, and in this context CAGR (i.e. Compound Annual Growth Rate) may be considered $18.0 \%$.Cloud computing is noticeable since the early 2000 s but the gradual development is important to note and most important is the latest development worldwide.
Though it is worthy to note that many potential service seekers were reluctant to implement Cloud Computing or allied services within their IT infrastructure due to certain issues including fund and security. Due to the understanding regarding the benefits of cloud computing by most of today's companies and as a result, they are moving to test workloads in the cloud and planning to migrate in the cloud [19], [30]. The Cloud Computing is ready to make Indian IT organizations with more on following features viz.

1. Flexibility,

2. Scalability, and

3. Security, etc.

\section{SUGGESTION}

Cloud Computing services are increasing day by day by different means and ways. As far as allied services are concerned it is also to be noted that such areas are also playing a leading role in the growth and development of the Cloud Computing Scenario. There are many things we need to understand before the installation of the Cloud, that we already learned. Proper funding, initiatives, research and development activities are highly required for a solid cloud computing system. Government rules, regulations and frameworks are highly required in the promotion of cloud systems and infrastructure in the nation. Further, proper technological support is also essential for continuous cloudbased services and thus different stakeholders need to attend on this important issue.

\section{CONCLUSION}

Regarding different types of Cloud Computing is concerned, major important are Public Cloud, Private Cloud and Hybrid Cloud Computing; and all these are useful based on need and situation. Hybrid cloud computing are increasing in different situation. Though the public cloud computing are most valuable and previously only IT companies are the users of cloud-based services but in recent past Government and Public undertaking, Government departments are also using Cloud based services. Both service providers and service seekers are not only from the developed countries but also from the developing countries are also noted well. Various service models are useful depending upon the situation and need. Service providers and consumers in a developing country viz. India is also increasing. There are various latest technologies and subcomponents of IT viz. Cloud Computing, Big Data Technologies, Data Analytics, Machine Learning, etc and all these are directly and indirectly responsible for cloud computing promotion and development.

\section{REFERENCES}

[1] Adamuthe, A. C., Salunkhe, V. D., Patil, S. H., \& Thampi, G. T. (2015). Cloud Computing-A market Perspective and Research Directions. International Journal of Information Technology and Computer Science (IJITCS), 7 (10), 42-53. 
[2] Alam, M. I., Pandey, M., \& Rautaray, S. S. (2015). A comprehensive survey on cloud computing. International Journal of Information Technology and Computer Science (IJITCS), 7 (2), 68.

[3] Assante, D., Castro, M., Hamburg, I., \& Martin, S. (2016). The use of cloud computing in SMEs. Procedia computer science, 83, 12071212.

[4] Channe, H., Kothari, S., \& Kadam, D. (2015). Multidisciplinary model for smart agriculture using internet-of-things (IoT), sensors, cloud-computing, mobile-computing \& big-data analysis. Int.J. Computer Technology \& Applications, 6 (3), 374-382.

[5] Etro, F. (2015). The economics of cloud computing. In Cloud Technology: Concepts, Methodologies, Tools, and Applications (pp. 2135-2148). IGI Global.

[6] Hou, X., Lu, Y., \& Dey, S. (2017, July). Wireless VR/AR with edge/cloud computing. In 2017 26th International Conference on Computer Communication and Networks (ICCCN) (pp. 1-8).

[7] Kumar, D., Baranwal, G., Raza, Z., \& Vidyarthi, D. P. (2017). A systematic study of double auction mechanisms in cloud computing. Journal of Systems and Software, 125, pp.234-255.

[8] Kumar, D., Samalia, H. V., \& Verma, P. (2017). Factors influencing cloud computing adoption by small and medium-sized enterprises (SMEs) In India. Pacific Asia Journal of the Association for Information Systems, 9 (3).

[9] Kumar, K. N., \& Vasuja, R. (2018). A Novel Scheme of Computing: Green Cloud Computing. International Journal of Scientific Research in Computer Science, Engineering and Information Technology IJSRCSEIT, 3 (3).

[10] Matos, R., Araujo, J., Oliveira, D., Maciel, P., \& Trivedi, K. (2015). Sensitivity analysis of a hierarchical model of mobile cloud computing. Simulation Modelling Practice and Theory, 50, 151-164.

[11] Meesariganda, B. R., \& Ishizaka, A. (2017). Mapping verbal AHP scale to numerical scale for cloud computing strategy selection. Applied Soft Computing, 53, 111-118.

[12] Mitra, A., O'Regan, N., \& Sarpong, D. (2018). Cloud resource adaptation: A resource based perspective on value creation for corporate growth. Technological Forecasting and Social Change, 130, 28-38.

[13] Mokhtar, S. A., Al-Sharafi, A., Ali, S. H. S., \& Al-Othmani, A. Z. (2016, May). Identifying the determinants of cloud computing adoption in higher education institutions. In 2016 International Conference on Information and Communication Technology (ICICTM) (pp.115-119). IEEE.

[14] Nordin, N. B., Mir, R. N., \& Noor, Z. (2017). Adoption of cloud computing in higher learning institutions: a systematic review. Indian Journal of Science and Technology, 10, 36.

[15] Paul, Prantosh Kumar, D Chatterjee, R Rajesh, K S Shivraj (2014). Cloud Computing: Overview, Requirement And Problem In The Perspective Of Undeveloped And Developing Countries With Special Reference To Its Probable Role In Knowledge Network of Academic Field. International Journal of Applied Engineering Research, 9 (26), 8970-8974.
[16] Pau1,Prantosh Kumar, K L Dangwal (2014) Cloud Computing Based Educational Systems and its challenges and opportunities and issues. Turkish Online Journal of Distance Education, 15 (1), 89-98.

[17] Pau1,Prantosh Kumar, \&Dipak Chaterjee (2012).Cloud Computing and Green Computing: Challenges \& Issues in Indian perspective. Asian Journl of Computer Science and Technology, 1 (2), 50-54.

[18] Paul,Prantosh Kumar , Ajay Kumar, M Ghosh (2012) Cloud Computing: the 21st Century Friend for Virtualization. Procedinngs of International Confernce of Computer Applications and Software Engineering, International Confernces-CASE-2012, 37-40.

[19] Pau1,Prantosh Kumar, S Govindarajan, Dipak Chaterjee (2013) Cloud Computing: Emphasizing Hybrid Cloud Computing on Android Computing Platform-An OverviewInternational Journal of Applied Science and Engineering,1 (1), 21-28.

[20] Paul, Prantosh Kumar (2013). Cloud Computing: Its Opportunities and Advantages with Special Reference to Its Disadvantages- A Study. International Journal of Neural Network and Application,6 (2), 84-88.

[21] Paul, Prantosh Kumar (2013). Cloud platform and the Virtualised World: Take a look. International Monthly Refereed Journal of Research in Management \& Technology, 2 (9), 112-119.

[22] Pereira, J., da Silva, E. O., Batista, T., Delicato, F. C., Pires, P. F., \& Khan, S. U. (2017). Cloud adoption in brazil. IT Professional, 19 (2), 50-56.

[23] Rathod, K. R. (2016). Cloud Computing-Key Pillar for Digital India. International Journal of Information, 6, ( 1/2 ), 27-33.

[24] Samimi, P., Teimouri, Y., \& Mukhtar, M. (2016). A combinatorial double auction resource allocation model in cloud computing. Information Sciences, 357, 201-216.

[25] Singh, J. (2017). Study on challenges, opportunities and predictions in cloud computing. International Journal of Modern Education and Computer Science, 9 (3), 17.

[26] Tafsiri, S. A., \& Yousefi, S. (2018). Combinatorial double auctionbased resource allocation mechanism in cloud computing market. Journal of Systems and Software, 137, 322-334.

[27] Vidhyalakshmi, R., \& Kumar, V. (2016). Determinants of cloud computing adoption by SMEs. International Journal of Business Information Systems, 22 (3), 375-395.

[28] Wease, G., Boateng, K., Yu, C. J., Chan, L., \& Barham, H. (2018). Technology assessment: cloud service adoption decision. In Infrastructure and Technology Management (pp. 447-471). Springer, Cham.

[29] Wang, B., Qi, Z., Ma, R., Guan, H., \& Vasilakos, A. V. (2015). A survey on data center networking for cloud computing. Computer Networks, 91, 528-547.

[30] Zhou, R., Li, Z., Wu, C., \& Huang, Z. (2016). An efficient cloud market mechanism for computing jobs with soft deadlines. IEEE/ACM Transactions on networking, 25 (2), 793-805. 